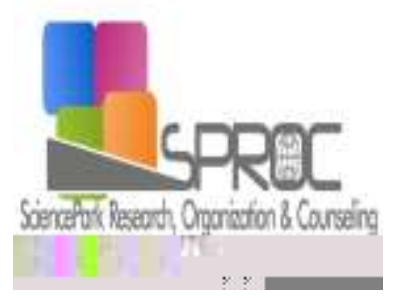

\section{New Trends and Issues Proceedings on Humanities and Social Sciences}

Volume 4, Issue 1 (2017) 555-557
'New Trends and Issues Proceedings on Humanities and Social Sciences

\begin{abstract}
ISSN 2421-8030
www.prosoc.eu

Selected Papers of 9th World Conference on Educational Sciences (WCES-2017) 01-04 February 2017 Hotel Aston La Scala

Convention Center, Nice, France
\end{abstract}

\title{
A student's approach to multiple representation
}

Melike Yagmur Tepedeldiren a*, Profesor Doktor Fuat Sezgin Fen Lisesi, 34210, Istanbul, Turkey.

Yusuf Tayfun Tepedeldiren ${ }^{b}$, Department of Mathematics, Yıldız Technical University, Davutpasa, 34210, Istanbul, Turkey.

\section{Suggested Citation:}

Tepedeldiren, Y. M. \& Tepedeldiren, T. Y. (2017). A student's approach to multiple representation. New Trends and Issues Proceedings on Humanities and Social Sciences. [Online]. 4(1), pp 555-557. Available from: www.prosoc.eu

Selection and peer review under responsibility of Prof. Dr. Jesus Garcia Laborda, University of Alcala, Spain. ${ }^{\circ} 2017$ SciencePark Research, Organization \& Counseling. All rights reserved.

\begin{abstract}
The Math lesson always seem to be the most difficult lesson to us as students. When you are faced with a problem, your approach may not be clear in the beginning so you must be directed by a supervisor. Your past experiences is of great importance but there must be some alternative ways to solve particular problems. I always believe that this lesson cannot be so hard to cope with. In this study we present a student's approach to multiple representation in math education. These problems presented to us are difficult to solve algebraicly but seem to be easy when trying to use multiple representations in the view of a student. This is important for our education system. The students take the university entrance exams to enroll a university. Students compete with the time. These kinds of methods made us to develop much more simplified methods to solve some particular problems.
\end{abstract}

Keywords: Background; geometrical approach; algebraic approach.

* ADDRESS FOR CORRESPONDENCE: Melike Yagmur Tepedeldiren, Profesor Doktor Fuat Sezgin Fen Lisesi, 34210, Istanbul, Turkey.

E-mail address: yusuftayfun1@gmail.com / Tel.: +23 554747831 


\section{Introduction}

When you learn math you realize that you often use algebraic approaches to a given mathematical problem although there are some alternative representations like geometrical approaches. The second approach is not seen very often, at least in my grade. Students in my class mainly show algebraic tendency to a given problem. When you think of it, you may ask yourself whether this can be changed or not using a certain method. In this study I will share my experiences to show how I use the multiple representation for math lessons (McCarthy, 1967; Ozkan, Tepedeldiren \& Unal, 2011).

\section{Methodology}

Before starting our study, I knew that I had a good level of math education and sufficient background. I had passed a hard exam to enrol this school. The school is one of the best schools in Turkey (The name is Profesor Doktor Fuat Sezgin Fen Lisesi) and most of the lessons are high level math based especially science lessons but I knew my insufficiencies. I could not develop good approaches to math based lessons before using geometrical approaches. I realised that when given a particular problem I always use algebraic representations. This may be reason of my insufficiency.

That is the point to change the direction. Is there an alternative way to cope with this difficulty. Of course there is another way that I applied. I tried to use geometrical approaches as much as possible. That made me feel better and understand more.

The Phythagorean Theorem is the most understandable theorem for me. When I was asked to prove the theorem I tried prove without adding any self-method (I did not add any individual information). I knew some certain numbers satisfy the Phythagoren Theorem. The proof is not geometrical (If it can be considered as a proof). I was also given the exact proof using vectors. That made the theorem much clear. I learned how to use vector algebra to prove such kinds of theorems and the angles between lines in three dimension. This approach is geometrical. But it is seen the effect of linear algebra and physics. Using vector algebra I also proved some Euclidean Relations.

At last my supervisor (also my father) directed me to use another geometrical approach and asked me to draw a table given below.

Table 1. Numerical approach the Phythagorean Theorem

\begin{tabular}{cccccc}
\hline $\mathrm{a}$ & $\mathrm{b}$ & $\mathrm{c}$ & $\mathrm{a}^{2}$ & $\mathrm{~b}^{2}$ & $\mathrm{c}^{2}$ \\
\hline 1 & 1 & 1.4 & 1 & 1 & 1.96 \\
1 & 2 & 2.3 & 1 & 4 & 5.23 \\
\hline
\end{tabular}

After doing this I had a fairly good information about the theorem. This is a kind of geometrical approach for this theorem. In this sense a relation had been established between an algebraic approach and geometrical approach. When using a table like this it means you are using a kind of geometrical approach. Geometrical approaches are not just geometrical figures and these also tables like this. When he directed me for proving the summation formula of $1+2+3+\ldots .+n=(n) .(n+1) / 2, I$ used a table given below.

Table 2. Numerical Approach to summation formula

\begin{tabular}{cccc}
\hline $\mathrm{n}$ & A:Summation & $\mathrm{A}-\mathrm{n}$ & $\mathrm{n}^{2}-\mathrm{A}$ \\
\hline 0 & 0 & 0 & 0 \\
1 & 1 & 1 & 1 \\
2 & 3 & 1 & 1 \\
3 & 6 & 3 & 3 \\
4 & 10 & 6 & 6 \\
5 & 15 & 10 & 10 \\
\hline
\end{tabular}


In this table again we used a geometrical approach for the summation formula. I could realize the equality of $A-n$ and $n^{2}-A$. It just remains to equalize them and find $A$. Using this information I get the desired result. This specifically works when you try inductive methods for math.

\section{Conclusion}

In this study we mainly focused on the geometrical approach for proving some of the theorems. We don't give any information how we are successful for using this method. It means we don't generalize my success to every kind of problem. The success may depend on students. We just gave some samples about multiple representations for math lessons. This subject is open to further explorations. The high level background allowed me to get the desired result. But is it always possible? Can the students always be directed for using geometrical approach? If it is so, what will we gain in return for it?

\section{References}

McCarthy, J. (1967). A basis for a mathematical theory of computation. Corrected Version of Western Joint Computer Conference, 10, 30-69.

Ozkan, E. M., Tepedeldiren, Y. T. \& Unal, H. (2011). Geometrical and algebraic approach to multiple representations. Procedia-Social and Behavioral Sciences, 15, 72-75. 